\title{
PRODUÇÃO DE TECIDOS NÃOTECIDOS ELETROFIADOS COM ATIVIDADE CICATRIZANTE
}

\author{
M. M. de AZEVEDO ${ }^{1}$, R. B. VENTURELLI ${ }^{2}$, R. C. S. C. VALLE ${ }^{1}$, E. FONTANA ${ }^{1}$, A. A. \\ ULSON DE SOUZA ${ }^{2}$, A. P. S. IMMICH ${ }^{1}$ \\ ${ }^{1}$ Universidade Federal de Santa Catarina, Campus de Blumenau, Engenharia Têxtil, \\ Blumenau - SC \\ ${ }^{2}$ Universidade Federal de Santa Catarina, Departamento de Engenharia Química e \\ Engenharia de Alimentos, Florianópolis -SC \\ E-mail para contato: ana.immich@ufsc.br
}

\begin{abstract}
RESUMO - Eletrofiação é uma forma de obtenção de nãotecidos através de uma diferença de potencial elétrico. Estes nãotecidos têm grande utilidade na área biomédica agindo como curativos e coberturas de feridas. Os nãotecidos podem, no processo de eletrofiação, receber substâncias ativas que conferem funcionalidade aos materiais. O objetivo deste trabalho é desenvolver um curativo, através de um nãotecido eletrofiado de policaprolactona e conferir a este nãotecido propriedades cicatrizantes e antibacterianas com adição de Aloe vera. Através do processo de eletrofiação e otimização das condições de trabalho, foram construídas amostras de nãotecidos de policaprolactona contendo Aloe vera, cuja liberação foi estudada em soro fisiológico a $37{ }^{\circ} \mathrm{C}$. Neste estudo, observou-se o comportamento de liberação da Aloe vera em meio fisiológico e constatou-se que o transporte total ocorre em um curto período de tempo devido à alta solubilidade da Aloe vera, porém, mesmo após total liberação do agente cicatrizante, o nãotecido continua atuando como curativo passivo.
\end{abstract}

\section{INTRODUÇÃO}

Feridas cutâneas são definidas como a interrupção da continuidade da pele, podendo ser superficiais ou profundas. $\mathrm{O}$ tratamento clínico mais frequentemente utilizado para o tratamento das feridas é o curativo (Smaniotto et al., 2010).

É denominado curativo, o meio de tratamento de feridas que tem como objetivo proteção, limpeza, estancamento de hemorragia, drenagem de exsudados, alívio de dor e melhora no leito da ferida. Estes curativos podem ser classificados como curativos passivos, curativos inteligentes, curativos biológicos e curativos com princípios ativos. Como passivos entende-se curativos que apenas ocultam a ferida, os curativos com princípios ativos são curativos que em sua composição química possuem agentes com atividade específica no leito da ferida, comumente utilizados como antibacterianos, já os curativos inteligentes, são aqueles que em sua composição química possuem agentes que estimulam a cura da ferida, estimulando respostas biológicas direcionadas á cicatrização (Fan et al.,2011). 
Para a fabricação de curativos são comumente utilizados tecidos de algodão estéreis, papel, seda e em uma crescente escala os biopolímeros. Atualmente biopolímeros, polímeros obtidos em maior parte por biossíntese de plantas, animais e bactérias, estão apresentando ótimos resultados em aplicações biomédicas por serem biocompatíveis e biodegradáveis, como exemplos temos o poli(ácido láctico), quitosana e a policaprolactona. Uma forma de processamento dos biopolímeros que atualmente está sendo muito estudada é a eletrofiação (Immich et al., 2013).

No processo de eletrofiação, uma solução polimérica é inserida em um campo elétrico através de uma seringa com agulha ou capilar de diâmetro definido. Quando a tensão aplicada na solução polimérica for maior que a tensão superficial da gotícula formada na extremidade do capilar, esta solução de polímero é estirada e transformada em fio. Este fio é coletado de forma desordenada por uma base metálica com polaridade contrária à solução. (Ramos, 2011).

Através do processo de eletrofiação, novas propriedades podem ser incorporadas aos nãotecidos alterando suas características químicas e/ou físicas e conferindo uma funcionalidade ao material. Como agentes ativos em nãotecidos aplicam-se, por exemplo, nanocápsulas de prata como agente antimicrobiano, soluções com cálcio para estimular a hemostase, óleos essenciais e extratos de plantas com o objetivo de analgesia e atividades antimicrobianas (Smaniotto, 2010).

Filadelpho (2009) obteve resultados positivos quanto à aplicação de Aloe vera para a cicatrização de feridas em dorso de ratos. Em seus estudos, Ramos e Pimentel (2011) afirmam concretamente a eficácia da planta na cicatrização da pele, observando também a comprovação do mecanismo antiinflamatório e antioxidante.

Visando o mercado de curativos funcionais, este trabalho propõe o estudo de nãotecidos eletrofiados de um material biocompatível com a incorporação simultânea de agentes com atividade cicatrizante como a Aloe vera, visto que atualmente não existem muitas opções na área de curativos funcionais com princípios ativos, bem como as opções comerciáveis têm valores inacessíveis para a maioria dos pacientes.

\section{OBJETIVOS}

Como objetivos deste trabalho propõem-se o estudo e aprimoramento da técnica de eletrofiação para produção de nãotecido polimérico com a incorporação de propriedades cicatrizante, como uma alternativa para curativos médicos.

\section{MATERIAIS E MÉTODOS}

O trabalho foi realizado no Laboratório de Transferência de Massa (Labmassa) do Departamento de Engenharia Química e Engenharia de Alimentos da Universidade Federal de Santa Catarina.

\subsection{Materiais}

Para preparo das soluções poliméricas a serem eletrofiadas foram utilizados policaprolactona fornecido por Purac, dimetilformamida $\left(\mathrm{CH}_{3}\right)_{2} \mathrm{NCH}$ com pureza de 99,9\% 
(Sigma-Aldrich) e clorofórmio $\left(\mathrm{CHCL}_{3}\right)$ com pureza de 99,8\% (VETEC). Para o preparo das soluções aquosas, foi utilizada Aloe vera em pó diluído em água destilada na proporção de 1:200 fornecida por Mix Brasil Produtos Naturais Eireli - ME.

\subsection{Métodos}

Preparo das soluções a serem eletrofiadas: Foram preparadas quatro soluções poliméricas para a escolha da solução mais adequada para o processo de eletrofiação. As composições das soluções poliméricas são apresentadas na Tabela 1.

Tabela 1 - Concentrações das soluções poliméricas.

\begin{tabular}{ccccc}
\hline Amostra & Polímero & Solventes & Concentração \% & Dimetilformamida \% \\
\hline I & PCL & Clorofórmio & 5 & - \\
II & PCL & Clorofórmio & 7 & - \\
III & PCL & Clorofórmio & 10 & - \\
IV & PCL & Clorofórmio & 10 & 10 \\
\hline
\end{tabular}

Preparo do nãotecido via processo de eletrofiação: Os parâmetros utilizados para o processo de eletrofiação foram: distância entre agulha e placa coletora de $12 \mathrm{~cm}$, taxa de infusão de $2 \mathrm{~mL} / \mathrm{h}$, tensão aplicada de $23 \mathrm{kV}$ e amostras contendo $1,5 \mathrm{~mL}$ de material a ser eletrofiado. A placa coletora foi integrada a um rotor com velocidade ajustada de 17 RPM, para que a dispersão das soluções fosse mais uniforme e atingisse toda a sua extensão. Durante a eletrofiação do polímero, a solução de Aloe vera foi pulverizada via electrospraying em uma seringa paralela à seringa do polímero.

Capacidade de entrega do Aloe vera: Para quantificar a liberação de Aloe vera a partir do nãotecido eletrofiado, foi utilizado um espectrofotômetro modelo UV mini 1240, marca Shimadzu. As amostras foram medidas no comprimento de onda de $200 \mu \mathrm{m}$.

A cinética de liberação do Aloe vera foi realizada em soro fisiológico a $37^{\circ} \mathrm{C}$, para simular a temperatura do corpo humano. Os ensaios de liberação foram realizados com as amostras de policaprolactona eletrofiada com adição de Aloe vera na concentração de $0,5 \%$. Periodicamente, alíquotas foram recolhidas do meio fisiológico e analisadas no espectrofotômetro para posterior cálculo de concentração de Aloe vera liberada.

Análise de microscopia eletrônica de varredura (MEV): A análise morfológica dos nãotecidos produzidos foi realizada por microscopia eletrônica de varredura em um microscópio eletrônico da marca JEOL, modelo JSM-6390LV.

\section{RESULTADOS E DISCUSSÕES}

\subsection{Processo De Eletrofiação}

A eletrofiação foi a técnica escolhida para confecção dos nãotecidos devido a possibilidade desta agregar aditivos funcionais ao nãotecido simultaneamente à confecção do 
mesmo. Para otimização da técnica, vários parâmetros foram analisados como viscosidade, distância entre agulha e coletor, vazão da bomba e tensão aplicada.

Inicialmente, observou-se que a viscosidade da solução polimérica influencia diretamente na qualidade do material eletrofiado. Observando o processo de eletrofiação das soluções, constatamos que a solução polimérica I, com $5 \%$ de policaprolactona, estava pouco viscosa, inviabilizando a formação de nãotecido. A eletrofiação da solução II, com $7 \%$ de polímero, viabilizou o processo, porém a qualidade do nãotecido formado era muito baixa. Estudos de McKee et al.(2012) constataram que quando o valor da concentração de polímero é muito baixo, o grau de entrelaçamento das cadeias poliméricas é baixo, causando uma instabilidade na extremidade do jato. Esta instabilidade pode ocasionar uma aspersão eletrostática ao invés de fiação eletrostática. As amostras com concentração de $10 \%$ apresentaram melhores resultados ao final do processo, com fibras mais uniformes, de diâmetro regular na escala submicrométrica, como mostra a imagem de microscopia eletrônica a seguir (Figura 1).

Figura 1 - Amostra de nãotecido eletrofiado de PCL, ampliação de 2000x

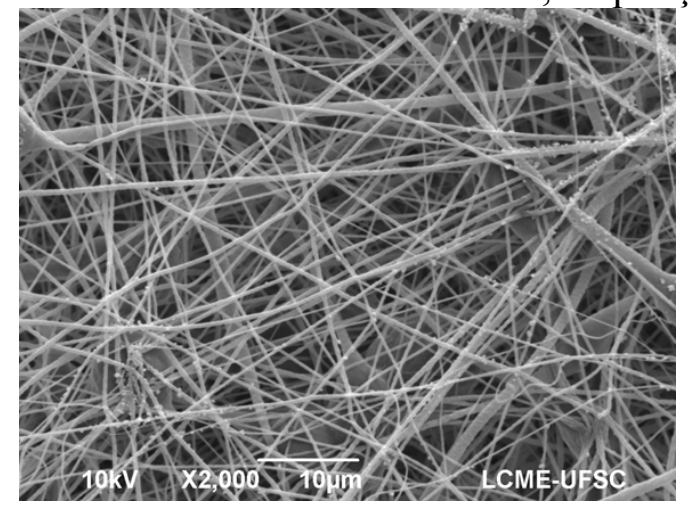

Observou-se, também, que vários parâmetros interferiram no processo de eletrofiação, entre eles a temperatura ambiente, que mostrou ter grande influência na viabilidade do processo. Elevadas temperaturas, próximas a $30{ }^{\circ} \mathrm{C}$, dificultaram o processo devido à alta volatilidade do solvente (ponto de ebulição de $61,2{ }^{\circ} \mathrm{C}$ ). Durante a eletrofiação o solvente evaporava antes do tempo requerido para a fiação e estiramento adequado das fibras.

Outro fator que influenciou a morfologia do nãotecido eletrofiado foi a constante dielétrica do solvente utilizado. Na eletrofiação da amostra III, com $10 \%$ de polímero, observou-se maior densidade do material eletrofiado, produzindo fibras uniformes, porém, o material distribuiu-se irregularmente pela placa coletora. Após adição de dimetilformamida à solução, com constante dielétrica maior que a do clorofórmio (38 e 4,81 respectivamente), observou-se que o material eletrofiado distribuiu-se mais uniformemente na superfície da placa coletora, facilitando a eletrofiação e a construção de um material homogêneo.

Os parâmetros como tensão aplicada e distância agulha/placa coletora foram facilmente controlados, uma vez que temperatura e constante dielétrica estavam bem controladas. A melhor tensão aplicada para viabilizar a formação da fibra foi encontrada em $23 \mathrm{kV}$. A distância entre agulha e placa coletora que proporcionou melhor estiramento e uniformidade do nãotecido coletado foi encontrada em $12 \mathrm{~cm}$. A taxa de infusão para alimentação da solução polimérica foi determinada coma a vazão mínima necessária para 
viabilizar a eletrofiação. Esta vazão foi padronizada em $2 \mathrm{~mL} / \mathrm{h}$. Estas condições foram mantidas para todos os nãotecidos produzidos com incorporação de Aloe vera. A Figura 2 apresenta a morfologia encontrada para estes materiais eletrofiados.

Figura 2 - Amostra do nãotecido eletrofiado de PCL com adição de 0,5 \% de Aloe vera, ampliação de 2000x.

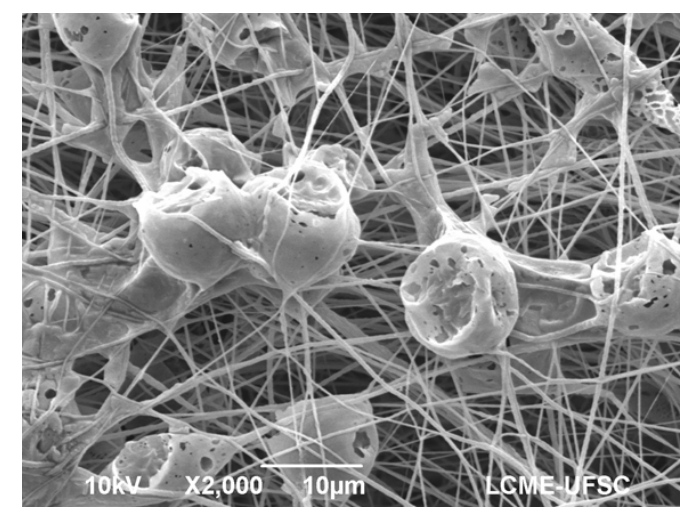

A Figura 2 mostra o nãotecido com adição de Aloe vera e pode-se perceber que o aditivo foi pulverizado uniformemente pela superfície e camadas internas do nãotecido. Porém, as fibras tiveram alteração de diâmetro, o que faz necessária a alteração dos parâmetros para uniformizar morfologia das fibras como diâmetro da fibra e porosidade do nãotecido.

\subsection{Cinética de liberação de Aloe vera}

Para análise de liberação do Aloe vera dos nãotecido eletrofiados, alíquotas foram retiradas do banho de liberação, conforme item 3.2. O gráfico da concentração de Aloe vera liberada versus tempo de liberação é apresentado na Figura 3.

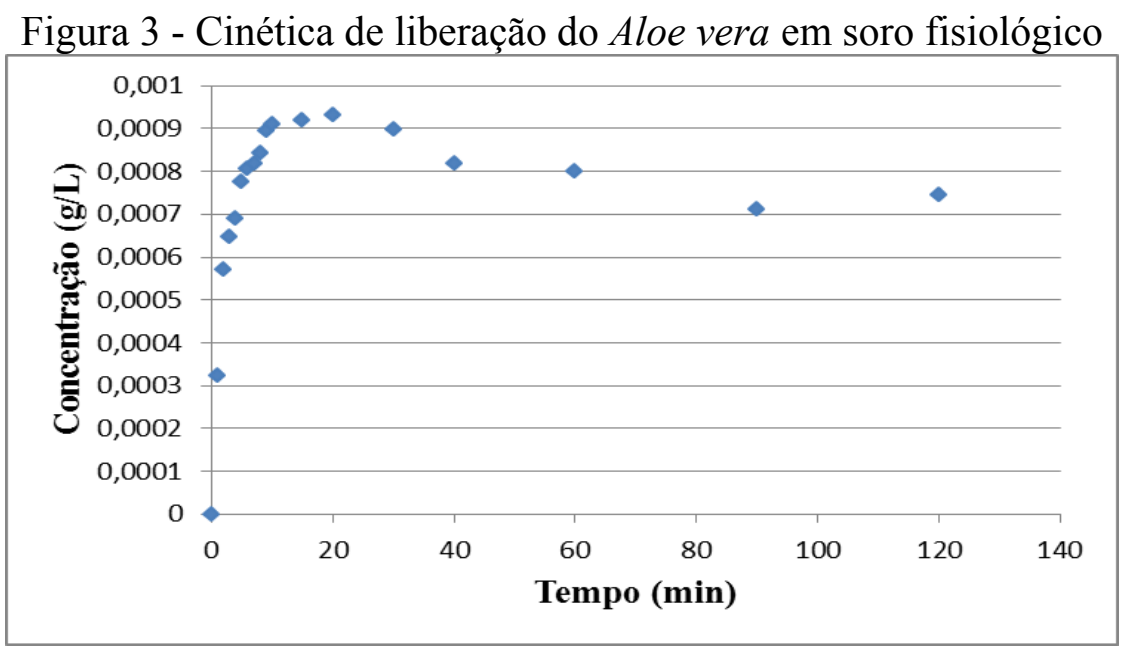

Observando a Figura 3 verifica-se que em aproximadamente uma hora a concentração de Aloe vera contida na amostra foi transferida para o meio, atingindo o equilíbrio cinético da liberação. A rápida liberação percebida nos primeiros minutos de ensaio está relacionada à 
alta solubilidade da substância no solvente testado, nesse caso, o soro fisiológico. No caso do uso sobre um ferimento, a rápida disponibilidade do agente cicatrizante torna-se interessante no sentido de intensificar o processo de cura da enfermidade, ficando o nãotecido agindo como um curativo passivo. Após atingir um pico por volta dos 20 min, uma pequena redução na concentração de Aloe vera é observada, sendo após isto atingido um estado permanente. Esta redução pode estar relacionada à degradação de determinadas substâncias em contato com o soro fisiológico ou com alguma mudança nas condições de equilíbrio entre o substrato têxtil e o meio líquido ao longo do tempo.

O ensaio de liberação mostrou ser eficiente, pois permitiu visualizar o processo de liberação do agente cicatrizante, simulando a cinética de entrega do mesmo ao tecido ferido. Estes dados podem ser empregados para determinar as melhores condições de produção e uso do material, como por exemplo a quantidade de Aloe vera que deve ser adicionada para aplicações em diferentes casos.

\section{CONCLUSÕES}

Este trabalho desenvolvido para produção de um nãotecido com a incorporação de um agente cicatrizante para tratamento de feridas representa uma alternativa aos métodos propostos até agora. O estudo mostrou que é possível eletrofiar o polímero PCL e aplicar o agente cicatrizante simultaneamente via electrospraying, produzindo fibras com diâmetros regulares e de baixa porosidade. Porém, mais estudos sobre a liberação da Aloe vera são necessários para estabelecermos um dispositivo de liberação uniforme e estável.

\section{REVISÃO BIBLIOGRÁFICA}

IMMICH, A. P. S.; ARIAS, M. L.; CARRERAS, N.; BOEMO, R. L.; TORNERO, J. A. Drug Delivery systems using sandwich configurations of electrospun poly(lactic acid) nanofiber membranes and ibuprofen. Material Science and Engineering C, v. C33, p. 4002-4008, 2013.

FAN, K.; TANG, J.; ESCANDON, J.; KIRSNER, R.S. State of the art in topical woundhealing products. Plast Reconstr Surg., v. 127(Suppl 1), p. 44S-59S, 2011.

MCKEE, M. G.; WILKES, G. L.; COLBY, R. H. \& LONG, T.E. - Macromolecules, v. 37, p.1760, 2004.

RAMOS, S. L. F. Membranas de policaprolactona obtidas por eletrofiação para utilização em engenharia tecidual. 2011. 77 f. Dissertação (Mestrado) - Curso de Engenharia Mecânica, Universidade Estadual de Campinas, Campinas, 2011.

SMANIOTTO, P.H.S.; GALli, R.; CARVALHO, V.F.; FERREIRA, M.C. Tratamento clínico das feridas - curativos. Rev Med (São Paulo), v. 89(3/4), p. 137-41, 2010. 